\section{Duodenal Strongyloides stercoralis Infection}

Strongyloides stercoralis infection is common in developing countries $(1,2)$, but it is a rare disease in Taiwan nowadays. The causative agents are the female worms in the mucosa of the duodenum and jejunum (3). The macroscopic changes of the minor forms show congestion, abundant mucous secretion, hemorrhage and micro-ulcerations. In the moderate to severe forms, edematous thickening of the wall, swelling of the folds, and destruction of the mucosal surface are found, leading to fibrosis and rigidity of the wall, mucosal atrophy, and ulcers (4), or even duodenal bulb deformity and obstruction (5). We present a 46-year-old male with the moderate to severe form of duodenal infection with Strongyloides stercoralis; he complained of diffuse abdominal fullness and pain without fever of chills lasting for four days. He had been given a diagnosis of rheumatoid arthritis five years previously, and had been taking penicillamine $250 \mathrm{mg} /$ day, naproxen $500 \mathrm{mg} /$ day and prednisolone $10 \mathrm{mg} /$ day since then. On admission, physical examination revealed a distended abdomen and diffuse tenderness. The white blood cell count was $5,400 / \mathrm{mm}^{3}$ with $4.4 \%$ eosinophiles, rising to $9 \%$ two days later. Hypovolemia and hypotension were treated with the administration of fluids. Diarrhea occurred on the sixth hospital day, but the stool analysis was normal. Fever, tachycardia, and low blood pressure $(70 / 50 \mathrm{~mm} \mathrm{Hg})$ developed on the seventh day after admission. Upper gastrointestinal tract endoscopy findings are shown in Figure 1; on a barium radiograph duodenal bulb deformity, mucosal thickness, a nodular appearance of the proximal descending duodenum, and a dilatation of the distal descending duodenum and jejunum were observed. The histological examination of the duodenal mucosa showed multiple larvae within the mucosa, with signs of acute and chronic inflammation (Figure 2). Mebendazole $200 \mathrm{mg} /$ day was given. However, the patient's condition worsened, and panperitonitis and ascites developed, with $E$. coli being cultured from the ascitic fluid. The patient finally died.

\section{References}

1 Milder JE, Walzer PD, Kilgore $G$, et al.: Clinical features of Strongyloides stercoralis infection in an endemic area of the United States. Gastroenterology 1981: 80: 1481-1408.

2 Blumenthal DS: Intestinal nematodes in the United States. N. Engl. J. Med. 1977; 297: 1437-1439.

3 Marcial-Rojas RA: Protozoal and helminthic diseases. In: Anderson WAD, Kissane JM (eds.). Pathology, 7th ed. St. Louis: Mosby, 1977; 522-565.

4 Poala D, Dias LB, Silva JR: Enteritis due to Strongyloides stercoralis. Am. J. Dig. Dis. 1962; 7: 1086-1098.

5 Bone MF, Chesner JM. Oliver R, et al.: Endoscopic appearances of duodenitis due to strongyloidiasis. Gastrointest. Endosc. 1982; 28: $190-191$.

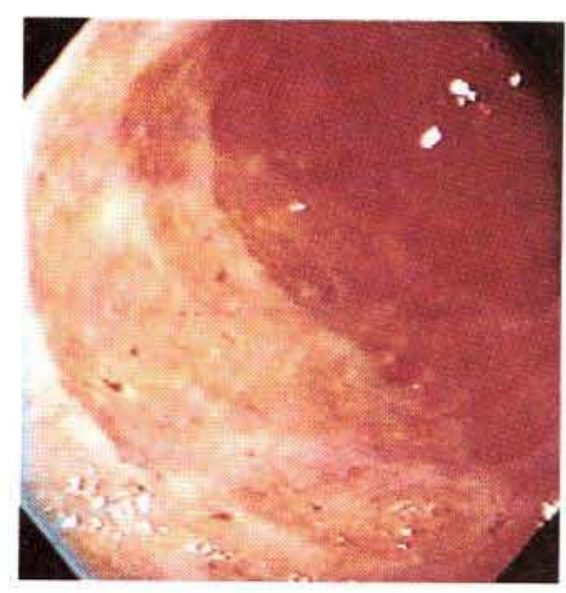

Figure 1: Endoscopic image showing flattening of the duodenal folds, swelling of the mucosa, and tiny ulcerations in the second part of the duodenum.

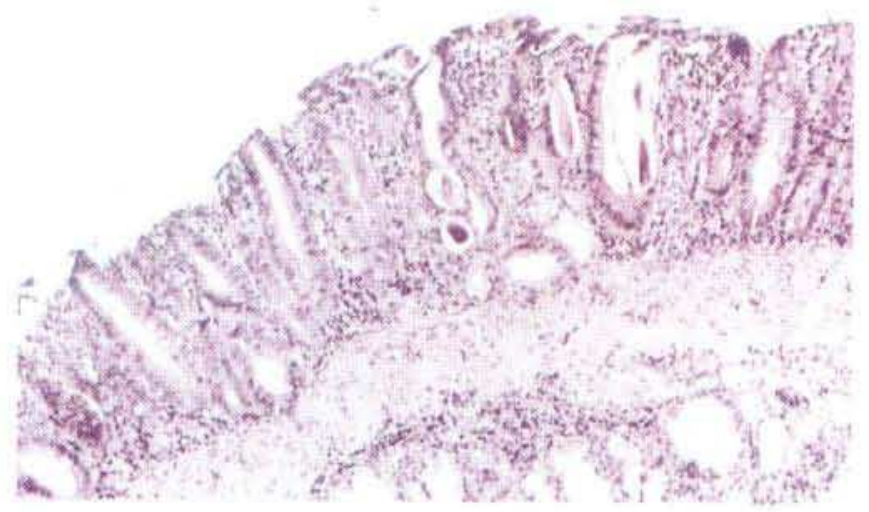

Figure 2: Histological examination of the duodenal mucosa, showing multiple intramucosal larvae with acute and chronic inflammatory cell infiltration $(\times 5)$.

\section{J.-J. Chen, C.-M. Lee, C.-S. Changchan}

Division of Gastroenterology, Department of Internal Medicine, Kaoshiung Medical Center, Chang Gung Memorial Hospital, 123 Ta-Pei Road, Naiosung, Kaoshiung Hsein, Taiwan 